\title{
La nueva Dama de Hierro de Europa: la creación de la imagen de Angela Merkel en la prensa española (estudio de caso de El Mundo)
}

institucional.us.es/ambitos/

\section{Miriam Suárez Romero \\ Universidad de Sevilla \\ mirsuarom@gmail.com}

English Version: Europe`s new iron lady. The creation of Angela Merkel's image in the Spanish press

\section{Resumen}

Este artículo analiza los textos de opinión publicados en el diario El Mundo sobre Angela Merkel durante las tres últimas elecciones federales alemanas (2005, 2009 y 2013), con el objetivo de analizar cómo se ha configurado la imagen que la

ciudadanía española tiene de la canciller alemana. En este sentido, el presente trabajo toma como punto de partida la consideración de los medios de comunicación como agentes fundamentales en la formación de la opinión pública y, por ello, actores determinantes de la opinión -como veremos-predominantemente negativa que tienen los españoles de la responsable germana.

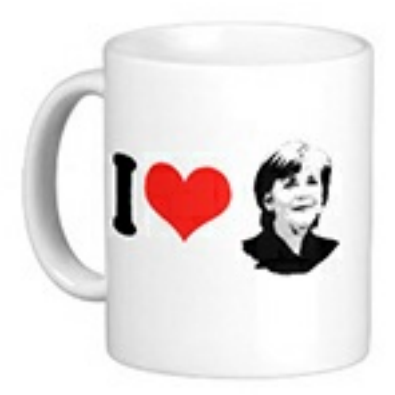

Palabras clave

Merkel, El Mundo, ideología, opinión pública, periodistas.

Abstract

This article analyzes the opinion pieces referring to Angela Merkel that have been published in the Spanish newspaper El Mundo during the week before and after the last three federal elections (2005, 2009 and 2013). In this sense, this article has its starting point in the consideration of the media as key players in the formation of public opinion and, therefore, as causative factors of the -as we will see- predominantly negative image that Spanish people have of German Chancellor.

\section{Keywords}

Merkel, El Mundo, ideology, public opinion, journalists.

\section{INTRODUCCIÓN}

Los medios de comunicación son fundamentales en nuestra sociedad. No sólo porque determinan la actualidad, sino porque, además, la interpretan para los ciudadanos, formando opiniones orientadas en función de unos intereses. Una persuasión que dirige nuestra forma de mirar hacia los acontecimientos y que construye, en definitiva, unas valoraciones que, según Walter Lippmann (2003), no son más que la reconstrucción de lo que otros han narrado y nosotros nos hemos imaginado.

Ante esta situación, son importantes los estudios que observen de forma crítica el papel de los medios de comunicación en la conformación de realidades para sus públicos. Y más aún en periodos de crisis, cuando los agentes sociales y políticos necesitan una legitimación de sus posiciones, ya sea orientando ideologías, desviando responsabilidades $\mathrm{o}$, directamente, buscando culpables. $Y$ en esta necesidad juegan un papel primordial los medios de comunicación, que actúan como sus portavoces atendiendo a un complejo entramado de intereses que van más allá de lo meramente informativo. En este proceso, la conformación de las opiniones publicadas en los diarios puede entenderse como el resultado de una actividad que excede los límites de la información y se acerca a las labores propias de la propaganda. 
Al hilo de estas reflexiones, nos preguntamos por qué en la sociedad española existe una opinión negativa sobre Angela Merkel y en qué medida los medios han construido ese sentir general, encauzando nuestro parecer o haciéndolo cambiar.

Son muchos los ejemplos que reflejan esta negativa actitud de los españoles hacia la canciller Merkel. El 6 de octubre de 2010, la edición electrónica de 20 minutos publicaba una noticia titulada "Los españoles suspenden a Merkel por ser 'egoísta', pero tienen buena imagen de Alemania", donde se comentaban los resultados de una encuesta de la empresa Metroscopia en la que Angela Merkel obtuvo 4.1 puntos de valoración. Según explicaba en ella el investigador del Real Instituto Elcano, Javier Noya, "existe cierta desafección de la sociedad española hacia los líderes políticos europeos en general, aunque especialmente la atención está puesta en Merkel".

Esta valoración puede observarse también en manifestaciones de la cultura popular como son los carnavales, siendo la canciller protagonista de numerosos ninots en las fiestas de distintas provincias. Ha sido representada como Mary Poppins en las Fallas de 2014 (1), sosteniendo una marioneta de cuyos hilos cuelga Rajoy en los carnavales de Vigo del año anterior, o incluso cogiéndolo en brazos, caricaturizado como un bebé.

La comprobación de que el rechazo hacia la canciller es la tendencia dominante la tenemos asimismo en las encuestas sociológicas. Tomemos como ejemplo el informe Transatlantic Trends, un sondeo anual de la opinión pública europea y estadounidense elaborado por el Fondo German Marshall (GMF) -una fundación con el objetivo de promover la colaboración y el entendimiento entre Europa y Estados Unidos- y la Compagnia di San Paolo -una de las fundaciones bancarias más importantes de Italia-, en la que colaboran también, entre otras instituciones, la Fundación BBVA. En el informe de resultados del duodécimo estudio, correspondiente a 2013, se concluye lo siguiente:

La valoración de la gestión de la crisis económica en Europa por parte de la canciller alemana Angela Merkel es algo más favorable: el $47 \%$ aprueba su gestión, frente al $42 \%$ que la desaprueba. No obstante, estas cifras varían mucho entre países: en Países Bajos, Alemania, Suecia y Francia, una amplia mayoría aprueba su gestión $(73 \%, 64 \%, 59 \%$ y $58 \%$, respectivamente), mientras que los tres países más afectados por la crisis España, Portugal e Italia- expresan una fuerte desaprobación (82\%, 65\% y $58 \%$ la desaprueba respectivamente) (p. 33)

La cifra de desaprobación de la población española es la más alta de todos los países miembros, incluyendo los afectados por la crisis económica. En este consenso han jugado un papel fundamental los medios de comunicación, puesto que todo lo que sabemos sobre la canciller es una mezcla de algo que hemos percibido junto con lo que extraemos de los medios, aunque, como apunta Noelle-Neumann (2011) -y predijo anteriormente Walter Lippmann-, terminamos creyendo, falsamente, que lo hemos extraído de nuestros propios razonamientos.

Estos son solo algunos de los ejemplos de la opinión generalizada que la ciudadanía española tiene sobre la canciller. Sin entrar en valorar la gestión de Angela Merkel, tratamos de vislumbrar el papel que ha jugado la prensa, y en concreto los autores que en ella plasman [sus] opiniones, en la formación de la imagen que tenemos de Merkel. Queremos comprender cómo y qué nos han contado para que Angela Merkel sea, en opinión de la ciudadanía española, la fría dueña de Europa.

\section{METODOLOGÍA}

\subsection{Definición del objeto de estudio}

Esta investigación tiene como objeto de estudio el posicionamiento editorial de El Mundo sobre Angela Merkel, y el respeto de los columnistas/articulistas del mismo medio a dicho posicionamiento durante las tres últimas elecciones federales en Alemania.

Si bien el periodismo no es aséptico en los textos informativos, los opinativos son la máxima expresión de lo que un medio quiere transmitir, de ahí su elección. En palabras de Escribano (2008:53): 
Los textos de opinión son uno de los pilares fundamentales de cualquier medio de comunicación, ya que en ellos se refleja, como en ningún [sic] otra sección, la ideología del grupo empresarial (político-económico) que lo sostiene. En este sentido, hay que tener en cuenta que el periodista trabaja para una empresa y que, a pesar de que el periodismo está concebido teóricamente como un servicio público, es, sobre todo, un intermediario político y social.

Teniendo en cuenta esto, nos interesa saber si hay un pluralismo real en el periódico, con cabida para voces disonantes o si, por el contrario, los autores de las piezas de opinión respetan el posicionamiento marcado en los editoriales, formándose una tendencia única en el tratamiento de la canciller. Ryszard Kapuściński (2007) describe la actividad del periodista como un debate entre su voluntad de independencia y la supeditación a los puntos de vista de la empresa para la que trabaja. Mediante la observación de los juicios vertidos podremos vislumbrar qué opción termina dominando lo publicado en El Mundo, y qué espacio hay en el periódico para la verdadera diversidad de opiniones.

La elección de Angela Merkel como protagonista está motivada por la escasez de estudios en profundidad acerca de cómo se ha orientado la opinión pública sobre la canciller a través de las informaciones y opiniones elaboradas por los medios de comunicación.

Todo lo que sabemos sobre ella ha pasado por diversos filtros mediáticos. Los periódicos han publicado todo tipo de informaciones, sobre todo en 2005 , cuando era una desconocida para los españoles. La prensa concentró sus esfuerzos en describirla, lejos de retratar su perfil profesional y sus políticas. La primera mujer canciller de la historia del país germano, doctorada en Física, era la hija de un reverendo luterano evangélico criada en la Alemania comunista para escándalo de sus compañeros de partido.

Dos aspectos destacan de forma clara en los textos de esta época: su apariencia física y su inexperiencia, como podemos constatar en los siguientes extractos periodísticos: "Antes de abandonar Templin camino de la universidad, Merkel tenía bien claras las enseñanzas de su familia: ser de las mejores y cuidar su interior, dejando a un lado lo exterior. De ahí le viene su poca atención y mimo al aspecto físico" (El Mundo, 2005, 19 de septiembre). Una valoración que, cuatro años más tarde, siendo ya conocida, se completa con la apreciación de que "Glamour tiene cero, pero inteligencia le sobra" (El Mundo, 2009, 27 de septiembre).

En las elecciones posteriores (2009 y 2013) este perfil se ampliará con otras cualidades imprescindibles para conocer la imagen pública de Merkel transmitida en la prensa española: el rol de madre de Alemania (Mutti Merkel) y su austera frialdad. Estas características, como indica Franziska Augstein (2011), han sido relacionadas por los medios de comunicación con su formación universitaria en Física y su educación en la República Democrática de Alemania.

Con respecto al periodo de estudio, se han seleccionado las tres últimas elecciones federales en Alemania (18 de septiembre de 2005, 27 de septiembre de 2009 y 22 de septiembre de 2013) por entender que este acontecimiento político genera un mayor caudal de información y opinión sobre este país y sus representantes políticos, sobre todo en la semana previa por la influencia que ejercen los periódicos en las valoraciones de los candidatos, y en la semana posterior por el comentario de los resultados de los comicios y las formaciones de gobiernos de coalición.

\subsection{Objetivos e hipótesis}

Una vez contextualizado el objeto de estudio, presentamos los objetivos de esta investigación:

- Determinar, mediante el análisis de contenido de las unidades seleccionadas, el posicionamiento de El Mundo respecto a la canciller alemana.

- Evaluar los posibles cambios en dicho posicionamiento en los tres momentos electorales seleccionados, con especial atención a lo sucedido desde 2008, año de inicio de la crisis económica.

- Determinar si dicha evolución ha creado una imagen distorsionada de Angela Merkel, tendente a resaltar sólo los aspectos negativos de la política alemana. 
- Valorar la diversidad ideológica de El Mundo, atendiendo al estudio comparativo entre los editoriales y el resto de textos de opinión.

De estos objetivos se derivan las siguientes hipótesis:

H1. El Mundo se ha posicionado en contra de Angela Merkel en sus textos de opinión, contribuyendo a formar una imagen negativa de la canciller en la sociedad.

H2. Los autores respetan la línea editorial marcada por el medio en las valoraciones que realizan de Angela Merkel, independientemente de su vinculación institucional.

H3. Los cambios en el tratamiento de la canciller en los tres momentos electorales responden a criterios esencialmente económicos.

\subsection{Selección del corpus de trabajo: los textos de opinión de El Mundo}

La elección de El Mundo para realizar el análisis responde al hecho de ser el diario de información general de ideología conservadora con más lectores al día en España, según los datos del Estudio General de Medios (EGM) para losúltimos años móviles (febrero a noviembre de los años 2005, 2009 y 2013) de la Asociación para la Investigación de Medios de Comunicación (AIMC).

Este periódico, fundado el 23 de octubre de 1989 con el nombre El Mundo del siglo XXI por Alfonso de Salas, Pedro J. Ramírez, Balbino Fraga, Juan González y Melchor Miralles, es un periódico liberal que ha sido tradicionalmente uno de los referentes de la derecha española, en concreto del Partido Popular -aunque ha tomado posturas críticas en momentos puntuales con algunos de sus dirigentes-, y uno de los detractores de los nacionalismos periféricos.

Durante todo el periodo de estudio ha contado con el mismo director, Pedro J. Ramírez, que ha ocupado el cargo hasta su cese el 30 de enero de 2014. El periódico es propiedad de Unidad Editorial, dueño también del Grupo Recoletos, ambos participados en gran medida por RCS Media Group.

Los textos seleccionados son los opinativos: editorial, columna, tribuna, carta del director, crítica y análisis. Si bien el periodismo no es aséptico en sus textos informativos, los textos opinativos son la máxima expresión de lo que un autor, periodista o el propio medio desea trasladar. A través de ellos estudiaremos qué imagen se difunde de Angela Merkel, porque la transmisión más explícita de ideología se realiza mediante este tipo de géneros en los medios.

El público lee el periódico, noticias positivas o negativas sobre Angela Merkel, que luego comentará con su entorno y cuyos argumentos repetirá. Y esto es lo que configura la opinión pública, lo que crea opiniones generalizadas y ambientes extendidos en pro o en contra de los temas en la sociedad. Y por extrapolación, en pro o en contra de Angela Merkel. Como indica Domenach (1955:126), "Detrás de un símbolo se ponen en movimiento ejércitos y muchedumbres; el motivo de un editorial da a millones de hombres la misma idea que conviene en un mismo día".

Ahora bien, no sólo estudiaremos la orientación editorial del medio, sino qué posicionamiento toman los autores de forma individual, para observar el grado de consonancia con la empresa a la que pertenecen. Así podremos comprobar si, como indica el diario de Unidad Editorial en su Libro de Estilo (1996), el medio sirve de plataforma al pluralismo ideológico de la sociedad gracias a la diversidad de opiniones (a veces contradictorias) en él publicadas.

De acuerdo con todas las indicaciones previas, el corpus de estudio está conformado por los textos de opinión de El Mundo en los que aparezcan referencias a Angela Merkel, publicados del 11 al 25 de septiembre de 2005, del 20 de septiembre al 4 de octubre de 2009, y del 15 al 29 de septiembre de 2013. Esto hace un total de 45 días durante los cuales se han analizado 40 textos periodísticos de opinión.

\subsection{El análisis de contenido}


La técnica seleccionada para el presente trabajo es el análisis de contenido, un método que, como indica Gómez Mendoza (2000), trata de descubrir la significación de un mensaje, clasificándolo y codificando los elementos que lo componen en categorías para que adquiera un sentido.

Combinamos tanto el análisis de contenido cuantitativo como cualitativo porque así podemos extraer conclusiones más enriquecedoras para nuestro propósito. Cuantitativo porque, en primer lugar, necesitamos conocer el valor del criterio "frecuencia", el número de veces que aparece Angela Merkel en los textos de opinión de El Mundo, para configurar el corpus. Cualitativo en tanto que vemos la presencia o ausencia de una característica de contenido mediante la cual podemos hacer inferencias y valorar las categorías tipificadas.

Tradicionalmente el análisis cualitativo ha ocupado un lugar secundario en la jerarquía de métodos frente a otros considerados más objetivos, criticándole siempre la sobrecarga de valores del investigador que contiene o la imposibilidad de generalizar sus conclusiones. No obstante, Martín López (1963: 63) ya hablaba de la necesidad de "desterrar cualquier prejuicio de carácter cuantitativo del análisis de contenido y centrarse constructivamente en el desarrollo de las posibilidades de esta técnica de investigación".

Todo análisis de contenido implica la descomposición minuciosa del material que se tiene en elementos de análisis que son clasificados en categorías. Para tal propósito, elaboramos la siguiente ficha de análisis:

- Nombre del codificador y fecha de codificación

- Fecha de publicación

- Tipo de texto

- Autor

- Vinculación institucional del autor con el medio

- Posicionamiento adoptado respecto a Angela Merkel

- Extractos del texto donde se aprecia el posicionamiento

Para determinar el tipo de texto de opinión, se han tenido en consideración las siguientes unidades de registro: editorial, columna, artículo, tribuna, carta del director, crítica y análisis.

Mediante la categoría referente al autor se pretende observar si las opiniones de periodistas, colaboradores habituales y grandes firmas son independientes respecto a la ideología de los periódicos analizados o si, por el contrario, se respetan sus líneas editoriales. Un ítem que se completa con el de la vinculación institucional con el medio. Partiendo del punto anterior, se estudia qué relación tiene el autor del texto con el periódico en ese momento. Consideraremos que está vinculado si el autor forma parte de la plantilla de El Mundo, en contraposición a las firmas que son colaboraciones esporádicas de personalidades notorias, periodistas de otros medios, políticos, profesores o firmas consideradas expertas en el tema, entre otros.

El posicionamiento adoptado respecto a la canciller se ha realizado mediante la categorización en positivo, negativo, o neutro, según se desprenda del tono general del texto a partir del análisis de su contenido. Así, el autor puede adoptar una actitud completamente favorable o desfavorable hacia Merkel, o puede no desprenderse ningún juicio categórico que permita englobarlo en los otros dos polos. Por último, se recogen los extractos literales de las piezas analizadas donde pueden encontrarse los argumentos en los que se aprecia tal posicionamiento.

\section{ANÁLISIS DE RESULTADOS}

En los periodos seleccionados encontramos un total de 40 piezas referentes a Angela Merkel: 10 en 2005, 8 en 2009 y 22 en 2013. Un 47,5\% hacen una valoración negativa y un 32,5\% positiva, siendo el $20 \%$ restante neutro. Más de la mitad de los textos fueron publicados en 2013 (55\%), seguido de 2005 (25\%) y por último 2009 (20\%). 
La primera consideración a tener en cuenta es que la orientación general de las piezas publicadas por El Mundo es negativa.

Para comparar el posicionamiento del medio con el de los autores de las piezas de opinión, separamos los seis editoriales con los que cuenta el corpus de estudio del resto de textos del género. En los editoriales se pone de manifiesto la línea editorial que el periódico ha adoptado respecto a la canciller, y nos servirán para testar la lealtad de sus autores a la línea marcada. Separamos además los autores vinculados con el medio (miembros de la plantilla o del Consejo Editorial) de los que no tienen vinculación.

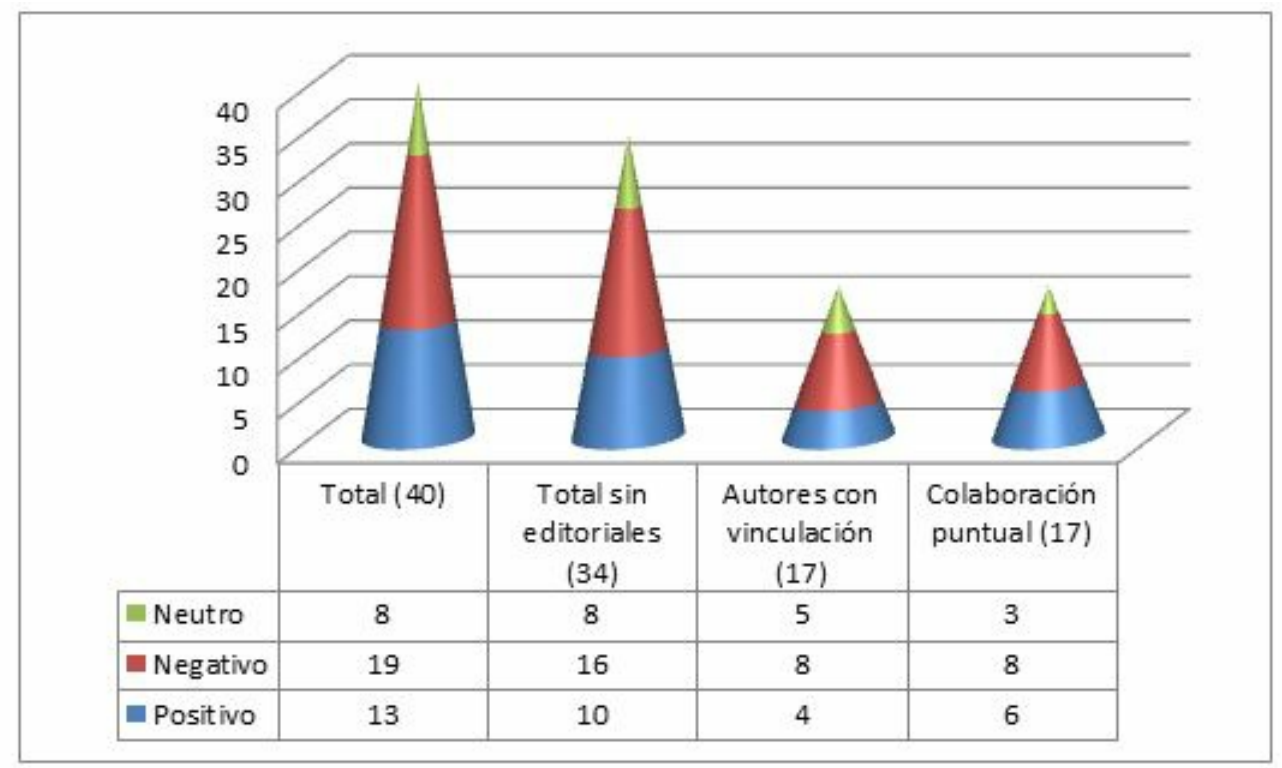

Gráfico 1. Comparativa general de los posicionamientos adoptados en los textos de El

Mundo. Fuente: Elaboración propia.

Como vemos en la gráfica anterior, las 34 piezas que no son editoriales se dividen del siguiente modo: 10 positivas, 16 negativas y 8 neutras.

Justo la mitad de ellas (17) están firmadas por personas con algún tipo de vinculación institucional con el medio. Por años varía la proporción, siendo la vinculación máxima en 2009 (57,14\% en 2005, 71,43\% en 2009, y un $40 \%$ en 2013). ¿Respetan estos autores la línea editorial fijada por su medio? En términos generales, sí. De los 17 textos de opinión de personas vinculadas, el $47 \%$ se posicionan de forma negativa respecto a la canciller, justo el doble que los posicionamientos positivos, y superior también al neutro.

Las situaciones contextuales de los tres periodos electorales son completamente diferentes, y el análisis individual arroja más luz que los datos generales, por lo que procedemos a un análisis detallado por años.

En 2005 Angela Merkel es casi una desconocida, y los distintos periódicos hacen sus apuestas sobre la nueva candidata. Se publican tres editoriales: dos negativos y uno positivo. El primero que encontramos es del 18 de septiembre (el día de las elecciones), titulado "Angela Merkel, un cambio probable y deseable". La orientación de este texto es, como ya anticipa su titular, positiva. Los argumentos esgrimidos para este juicio se basan en la importancia de las elecciones federales para el resto de Europa y en la idoneidad de las medidas propuestas por Merkel: "El triunfo de Merkel podría suponer un impulso para el relanzamiento de la economía alemana, ya que los democristianos han prometido el retorno a una política de disciplina presupuestaria y la profundización en la reforma del Estado de Bienestar".

El hándicap que ven en Merkel se basa en las dudas sobre su capacidad de liderazgo, algo secundario para el periódico puesto que los barones del partido le han dado su respaldo.

El candidato del SPD y por entonces canciller, Gerhard Schröder, realizó durante la legislatura anterior diversas reformas poco asociables al carácter socialdemócrata del partido al que pertenece, y El Mundo apoya su gestión en el mismo editorial: "El actual canciller ha hecho una buena campaña, centrada en su carisma personal y apelando a la necesidad de continuar las reformas iniciadas en la pasada legislatura, entre las que 
hay que destacar la bajada de la presión fiscal sobre la renta, el recorte del impuesto de sociedades, la eliminación de subsidios, la limitación de las prestaciones a los parados y la reforma de la Seguridad Social". El periódico, en todo caso, apuesta por la senda reformista, que será continuada por ambos candidatos. La diferencia radica en el nivel de intensidad.

Por ello al día siguiente, una vez conocidos los resultados de las elecciones, el hándicap sin importancia de la falta de liderazgo de Angela Merkel del día anterior se torna en un obstáculo insalvable en el editorial "Alemania, entre la 'Gran Coalición' y el 'Gobierno Semáforo' ”. Es la culpable de los malos resultados de la CDU (superó por muy poca diferencia al SPD): "A la luz de los resultados, parece claro que la democracia cristiana alemana se equivocó al elegir a Merkel como líder. Su campaña ha sido titubeante y ha cometido errores infantiles. Por el contrario, Schröder ha demostrado su férrea capacidad de lucha".

El rechazo a Merkel y el apoyo a Schröder radica en la tranquilidad de que, como hemos visto antes, ambos aplicarán las medidas liberales en lo económico que El Mundo considera adecuadas.

El tercero y último de los editoriales de este periodo electoral es publicado el 21 de septiembre, en pleno proceso de negociaciones, y se titula "Alemania, dos líderes débiles y un mal Gobierno". La CDU acababa de reelegir a Merkel, a pesar de lo que El Mundo califica como "decepcionantes resultados electorales". El posicionamiento de este editorial es negativo, igual que el anterior. El periódico cree que la peor consecuencia que podrían tener las elecciones es ya una realidad: "un Ejecutivo formado por un líder débil y partidos con programas tan dispares que será imposible emprender las reformas que Alemania, y en consecuencia toda la UE, necesita".

En los tres textos, lejos de apoyar a un candidato o un partido, se apoya a aquél -da igual la ideología- que aplique las reformas con mayor seguridad. En España no hay crisis en 2005, por lo que la asociación del futuro de Alemania no se hace directamente con España, sino con el futuro del conjunto de la Unión Europea (algo que cambiará en las siguientes elecciones federales).

El posicionamiento negativo de El Mundo es respetado por sus autores, cuyos textos adoptan este matiz en el $60 \%$ de los textos que analizamos. El siguiente cuadro recoge un resumen de los resultados de la clasificación por autores:

\begin{tabular}{|l|l|c|c|}
\hline \multicolumn{1}{|c|}{ Autor } & \multicolumn{1}{|c|}{ Vinculación con el medio } & $\mathrm{n}^{\circ}$ & Posic. \\
\hline EL MUNDO & Máxima & 3 & + \\
\cline { 3 - 4 } & & - \\
\cline { 3 - 4 } & & - \\
\hline $\begin{array}{l}\text { José María } \\
\text { Beneyto }\end{array}$ & $\begin{array}{l}\text { Colaboración puntual. Catedrático de Derecho } \\
\text { Internacional Público y Derecho Comunitario } \\
\text { Europeo y director del Instituto de Estudios } \\
\text { Europeos de la Universidad San Pablo CEU. }\end{array}$ & 1 & + \\
\hline José Luis Sanchís & $\begin{array}{l}\text { Colaboración puntual. Consultor político } \\
\text { español, director de más de cien campañas } \\
\text { electorales en Europa y América. }\end{array}$ & 1 & - \\
\hline Felipe Sahagún & $\begin{array}{l}\text { Alta. Miembro del Consejo Editorial de EI Mundo } \\
\text { y profesor de Relaciones Internacionales }\end{array}$ & 3 & $\mathrm{~N}$ \\
\cline { 3 - 4 } & & & - \\
\hline $\begin{array}{l}\text { Cayetana Alvarez } \\
\text { de Toledo }\end{array}$ & Alta. Periodista del medio & 1 & - \\
\hline $\begin{array}{l}\text { Tabla 1. Datos de autoría, vinculación institucional con El Mundo y posicionamiento } \\
\text { respecto a Angela Merkel en 2005. Fuente: Elaboración propia }\end{array}$ & \multicolumn{2}{|c|}{} \\
\hline
\end{tabular}

Queda saber si también realizan, como su medio, un giro en el tratamiento de la canciller antes y después de las elecciones, comprobación absoluta del respeto a la línea editorial marcada.

El Catedrático de Derecho Internacional Público y Derecho Comunitario Europeo y director del Instituto de Estudios Europeos de la Universidad San Pablo CEU, José María Beneyto, hacía una apuesta clara por la canciller antes de las elecciones en su artículo de opinión "Merkel conviene a Europa", del 16 de septiembre, en el que afirmaba: "Es más que probable que el electorado alemán sepa valorar afirmativamente este carácter a la vez firme y moderado con una victoria-sin duda, positiva para Europa- el próximo domingo". Dos días después, 18 de septiembre, publica "Merkel: un impulso para la economía europea", en el que se expresa 
abiertamente que si ganara, sería un estímulo para todas las mujeres que se dedican a la política, y convertiría de nuevo a Alemania en la locomotora de Europa, favoreciendo a España y a la Unión Europea.

Agapito Maestre, catedrático y filósofo, apela el mismo día a la necesidad de su victoria en el artículo "Merkel: un impulso para la economía europea": "si gana Merkel, y su programa de reformas económicas triunfa, convirtiendo a Alemania, otra vez, en la locomotora de Europa, también saldrían ganando todos los países de la Unión y, muy especialmente, España (...)".

Felipe Sahagún, miembro del Consejo Editorial de El Mundo, mantiene exactamente la misma causa superior que los editoriales en su artículo del 18 de septiembre, "Schröder: más vale lo malo conocido...", en el que concluye que "lo mejor para nuestro país es que, gane quien gane, impulse las reformas necesarias para sacar a la RFA del estancamiento económico en que se encuentra (...)". El mejor candidato no es conservador ni socialdemócrata, sino reformista, como marcan los editoriales.

No es lo único que respetan los autores del periódico. También radicalizan su postura hacia Merkel una vez conocidos los resultados, hasta el punto de que se achaca la responsabilidad de las buenas e inesperadas cifras del SPD a la misma Angela Merkel a la que en días anteriores se referían como la persona que devolvería el esplendor al país germano, como expresa el mismo Felipe Sahagún el día 19 en "Dos opciones":"Las claves de la remontada son la confusión del programa político conservador, sobre todo en materia fiscal, el miedo de muchos alemanes a perder el estado de bienestar convenientemente atizado por Schröder y las serias limitaciones de Angela Merkel como candidata".

Ahora es una "candidata gris", culpable de que peligre la posibilidad de que se forme un Gobierno convenientemente reformista. Tanto es así que este miembro del Consejo Editorial vaticina, sin mucho acierto, el fin de Merkel en "Claves para entender los resultados", publicado el 20 de septiembre: "la candidata cristianodemócrata ha sufrido un duro varapalo y, probablemente, se verá forzada a dimitir en poco tiempo".

El resto de firmas siguen la misma línea. En la columna "El cielo se desploma", Cayetana Álvarez de Toledo, periodista del medio, aseguraba casi una semana después de las elecciones que los resultados suponían el fiasco del reformismo alemán, y que "el huracán Merkel resultó ser una ligera brisa y una calamidad mediática".

En contra de lo vaticinado por todas las firmas de El Mundo y por el periódico mismo, llegamos a 2009, y Angela Merkel vuelve a ser elegida canciller. Tan sólo aparece en dos piezas antes de las elecciones ( $\mathrm{y}$ una de ellas le dedica una sola frase). Ya no hay vaticinios en editoriales ni autores que hagan sus apuestas, pero siguen predominando las piezas negativas $(50 \%)$ frente a las positivas y neutras:

\begin{tabular}{|l|l|c|c|}
\hline \multicolumn{1}{|c|}{ Autor } & \multicolumn{1}{|c|}{ Vinculación con el medio } & $\mathrm{n}^{0}$ & Posic. \\
\hline EL MUNDO & Máxima & 1 & + \\
\hline Ana Romero & Alta. Periodista del medio & 3 & + \\
\cline { 2 - 4 } & & - & - \\
\hline Pedro J. Ramírez & Alta. Director del medio & 1 & $\mathrm{~N}$ \\
\hline Heribert Prantl & $\begin{array}{l}\text { Colaboración puntual. Jefe de Política } \\
\text { Nacional del Süddeutsche Zeitung }\end{array}$ & 1 & - \\
\hline $\begin{array}{l}\text { ERASMO (José } \\
\text { Luis Gutiérrez) }\end{array}$ & $\begin{array}{l}\text { Alta. Periodista del medio, columna diaria. } \\
\text { Uno de los fundadores de la revista } \\
\text { Gentleman, y exdirector de Diario 16 }\end{array}$ & 1 & - \\
\hline $\begin{array}{l}\text { Carlos Mulas, } \\
\text { Matt Browne }\end{array}$ & $\begin{array}{l}\text { Colaboración puntual. Carlos Mulas es } \\
\text { director de la Fundación Ideas, Matt Browne } \\
\text { es miembro del Center for American } \\
\text { Progress }\end{array}$ & 1 & $\mathrm{~N}$ \\
\hline $\begin{array}{l}\text { Tabla 2. Datos autoria, vinculación institucional con El Mundo y posicionamiento } \\
\text { respecto a Angela Merkel en 2009. Fuente: Elaboración propia }\end{array}$ & \\
\hline
\end{tabular}

La situación ha cambiado desde las primeras elecciones, puesto que ha pasado a formar parte activa de la política española a través de su papel de liderazgo en la Unión Europea, Alemania ha salido de la crisis y España comienza la suya. En el único editorial del que es protagonista en este año analizado, "Los alemanes votan por una rebaja fiscal", El Mundo atribuye su reelección al "liderazgo internacional que ha ejercido durante la crisis". Una canciller que, expresa este editorial del 28 de septiembre, ha visto revalidada en las urnas su gestión al frente del Gobierno de gran coalición (que finalmente se formó con CDU y SPD, en contra de las 
advertencias de El Mundo en 2005, para el que la unión de los dos grandes partidos era del todo desaconsejable por la mala experiencia de los años 60).

Sigue estando de fondo la economía como factor decisivo en las elecciones. Si antes la apuesta por las reformas era clara, ahora esta apreciación del diario viene, según este mismo editorial, respaldada por los alemanes, puesto que "los comicios suponían todo un test acerca de las políticas que los ciudadanos consideran más adecuadas para combatir la recesión y volver a la senda del crecimiento". Este año, el partido liberal FPD consigue un alto porcentaje de los votos, razón del titular de este editorial: los alemanes votan por una rebaja fiscal.

Y, de nuevo, el resto de piezas de opinión vuelven a seguir la línea marcada por el editorial. Este año ya no se hacen llamadas al reformismo ni se cuestiona el liderazgo de Merkel, tópicos principales de las elecciones anteriores. Ahora la pauta está centrada en los liberales del FDP, que pueden radicalizar las políticas económicas que El Mundo considera deseables y de las que España se aleja cada vez más, pues un año antes, en 2008, José Luis Rodríguez Zapatero revalidó su cargo al frente del Ejecutivo español. Todas las piezas irán encaminadas a demostrar la idoneidad de las políticas liberales en lo económico.

Tanto es así que la idea generalizada de los artículos de este periodo pasa por disminuir la importancia de los resultados de Angela Merkel y relativizarlos en función de los que consideran los verdaderos buenos resultados: los del FDP, compañeros de coalición de la CDU este año: "En adelante no podrá esconderse detrás del SPD. (...) Si Angela Merkel vuelve a jugar el papel de madre de la nación, tendrá dificultades con el FDP y con su partido. Si se convierte en dama de hierro perderá su reputación y su renombre entre el pueblo. La edad dorada de Merkel ha pasado", argumenta el día después de los comicios Heribert Prantl, jefe de Política Nacional del Süddeutsche Zeitung, en "Doble amarillo y negro".

Todo se articula en torno al giro más liberal que puede dar Alemania. Es el caso, por ejemplo, del brevete titulado "Merkel" y firmado por Erasmo, seudónimo de José Luis Gutiérrez (uno de los fundadores de la revista Gentleman y exdirector de Diario 16): "Y esta Angela: el vasto mundo de Leipzig, aquel pasillo de Danzig, "agitprop", comunista juvenil mutó, en democristiana: ahora con liberales".

Mismo tema y mismo tratamiento negativo a Angela Merkel. La unión de estos dos factores marca el tono general de lo publicado, si bien cada autor lo hace de distinta forma. Ana Romero, corresponsal en Berlín, asocia en una columna del 28 de septiembre, titulada "De Maggie a Angie", a la canciller alemana con Margaret Thatcher, si bien no es precisamente por su política económica:

La nueva Dama de Hierro de Europa (...) una investigadora física criada en Alemania Oriental y que durante cuatro años ha tenido que frenar sus instintos reformadores. La británica le gana con creces en feminidad (...) Una persona que por su trabajo en el Reino Unido y en Alemania ha conocido a ambas políticas me describió a Merkel como 'una ameba': 'No es ni hombre ni mujer. Tiene la misma sexualidad que esto', añadió, señalando al salero de la mesa. Miro a Merkel otra vez. Como siempre, con sus pantalones oscuros. Con los dedos unidos, como si fuera su padre predicando desde el púlpito en Brandemburgo. Por arriba, la chaqueta, el top y la gargantilla de siempre. (...) ha demostrado que los alemanes la quieren más a ella que al partido. Su estrategia ha funcionado: no hablar de casi nada, aburrirlos a muerte y que confíen en ella. (...) También dice que nadie la menosprecie, porque bajo esa apariencia afable, Merkel escaló al poder pisando a dos de sus padrinos, Lothar de Maizière y Helmut Kohl.

Reducir a Angela Merkel a una ameba, analizar su vestimenta, encajar sus logros con ironía como fruto del aburrimiento de los alemanes y destacar la faceta maligna de su lado personal, por traicionar a su mentor Helmut Kohl, son elementos que no desentonan entre lo publicado por la prensa española en 2009.

Los periódicos conservadores consideran las medidas de Merkel débiles y los progresistas demasiado fuertes. Entre los primeros podemos englobar a El Mundo que, además de definir su línea editorial como liberal, lo demuestra. En 2005 llamaba a la coalición con los socialdemócratas de Schröder para continuar con las medidas reformistas emprendidas por el canciller, pero en 2009, tras la primera legislatura de Merkel, considera que es necesaria una radicalización de las acciones económicas, por lo que llama al apoyo del Partido 
Democrático Liberal (FDP), cuya prioridad política es reforzar el libre mercado y aplicar el liberalismo clásico.

Y con esta apuesta por un Gobierno más liberal llegamos a 2013, las terceras elecciones federales alemanas en las que es reelegida Angela Merkel como canciller, de las que sale más reforzada que nunca. El Mundo le dedica dos editoriales, ambos con un posicionamiento general positivo, si bien el editorial posterior a las elecciones es bastante más claro que el previo, mucho menos categórico.

Visto que la coalición CDU-FDP, por la que en la anterior legislatura apostaban, no salió como esperaban, en el editorial publicado el día que se celebran las elecciones la formación recomendable es la integrada de nuevo por CDU y SPD, con elogios al candidato socialdemócrata incluidos en el editorial "Por qué a la UE le conviene una gran coalición en Alemania": "La canciller democristiana se ha presentado como la defensora de la clase media y de una política razonable de austeridad mientras que Peer Steinbrück, el líder del SPD, un dirigente impulsivo y brillante, ha tratado de limar sus aristas y acercarse al ciudadano de a pie".

En el mismo editorial se nos da la clave del posicionamiento adoptado para esta legislatura: "Alemania no aceptará jamás la mutualización de la deuda a través de la emisión de eurobonos. Por ello, la mejor opción para Europa es un Gobierno entre la CDU-CSU y el SPD, que podría aportar una mayor sensibilidad hacia el sur". Estoes fundamental para entender el posicionamiento de este año y el porqué de las apuestas abiertas realizadas en el periódico por la repetición de un gobierno de coalición entre los dos grandes partidos: "Hay que recordar que fue en el periodo 2005-2009 cuando esa coalición de los dos grandes partidos abordó las reformas que posibilitaron el boom alemán posterior", se expresa en el mismo texto.

Pero en el segundo editorial, "Merkel entra en la historia con su tercera victoria", publicado el 23 de septiembre y por tanto conocida ya la victoria aplastante de Merkel, ya no es tan necesario el SPD. Nos encontramos fragmentos como el siguiente: "Parafraseando una antigua estrofa del tradicional himno alemán que proclama que Alemania está 'por encima de todo', su gran victoria sitúa a Angela Merkel ciertamente überalles tras arrollar a todos su oponentes". El editorial termina diciendo que "los votos han convertido a Merkel en la dirigente europea más importante del siglo XXI para sorpresa de muchos que han menospreciado a la hija de un pastor luterano en la que pocos creían" (empezando por el periódico mismo).

El tono general positivo, más acentuado en las piezas post-electorales, es respetado por el resto de firmas, si bien hay una disminución considerable de la diferencia: siete son positivas,ocho negativas y cinco neutras, como podemos observar en el siguiente cuadro de resultados: 


\begin{tabular}{|c|c|c|c|}
\hline Autor & Vinculación con el medio & $\mathrm{n}^{0}$ & Posic. \\
\hline \multirow[t]{2}{*}{ EL MUNDO } & \multirow[t]{2}{*}{ Máxima. } & \multirow[t]{2}{*}{2} & + \\
\hline & & & + \\
\hline Mark Schieritz & Alta. Periodista de Die Zeit. & 1 & $\mathrm{~N}$ \\
\hline $\begin{array}{l}\text { Pedro G. } \\
\text { Cuartango }\end{array}$ & $\begin{array}{l}\text { Alta. Columnista de El Mundo, en } 2000 \text { es } \\
\text { nombrado subdirector y responsable de la } \\
\text { sección Opinión (y en 2014, adjunto al } \\
\text { director). }\end{array}$ & 1 & + \\
\hline Ute Müller & $\begin{array}{l}\text { Colaboración puntual. Corresponsal de } \\
\text { Die Welt en España y Portugal. }\end{array}$ & 1 & $\mathrm{~N}$ \\
\hline Helene Zuber & $\begin{array}{l}\text { Colaboración puntual. Corresponsal del } \\
\text { semanario Der Spiegel en la Península } \\
\text { lbérica. }\end{array}$ & 1 & + \\
\hline $\begin{array}{l}\text { Antonio García } \\
\text { Santesmases }\end{array}$ & $\begin{array}{l}\text { Colaboración puntual. Catedrático de } \\
\text { Filosofía Política de la UNED. }\end{array}$ & 1 & - \\
\hline $\begin{array}{l}\text { Hans-Gert } \\
\text { Pöttering }\end{array}$ & $\begin{array}{l}\text { Colaboración puntual. Director de la } \\
\text { Fundación Konrad Adenauer, } \\
\text { expresidente del Parlamento Europeo y } \\
\text { eurodiputado por la CDU desde } 1979 .\end{array}$ & 1 & + \\
\hline $\begin{array}{l}\text { SECONDAT } \\
\text { (Manuel } \\
\text { Jiménez de } \\
\text { Parga) }\end{array}$ & $\begin{array}{l}\text { Colaboración puntual. Jurista y político } \\
\text { español (UCD). }\end{array}$ & 1 & - \\
\hline $\begin{array}{l}\text { Casimiro García- } \\
\text { Abadillo }\end{array}$ & $\begin{array}{l}\text { Alta. Periodista del medio (en } 2014 \text { ocupa } \\
\text { el puesto de director de El Mundo). }\end{array}$ & 1 & - \\
\hline Juan Moreno & $\begin{array}{l}\text { Colaboración puntual. Escritor y } \\
\text { periodista, colabora en el semanario } \\
\text { alemán Der Spiegel. }\end{array}$ & 1 & - \\
\hline $\begin{array}{l}\text { Juergen } \\
\text { B.Donges }\end{array}$ & $\begin{array}{l}\text { Colaboración puntual. Cologne Institute } \\
\text { for Economic Policy }\end{array}$ & 1 & + \\
\hline Ulrich Beck & $\begin{array}{l}\text { Colaboración puntual. Sociólogo alemán y } \\
\text { profesor de la Universidad de Múnich y de } \\
\text { la London School of Economics. }\end{array}$ & 1 & - \\
\hline Sánchez Dragó & Alta. Escritor del medio. & 1 & + \\
\hline Felipe Sahagún & $\begin{array}{l}\text { Alta. Miembro del Consejo Editorial de El } \\
\text { Mundo. }\end{array}$ & 1 & + \\
\hline John Müller & Alta. Periodista del medio. & 1 & - \\
\hline $\begin{array}{l}\text { Enrique } \\
\text { Gimbernat }\end{array}$ & $\begin{array}{l}\text { Alta. Catedrático de Derecho Penal de la } \\
\text { Universidad Complutense de Madrid y } \\
\text { miembro del Consejo Editorial de El } \\
\text { Mundo. }\end{array}$ & 1 & $\mathrm{~N}$ \\
\hline Claudio Magris & Colaboración puntual. Escritor italiano. & 1 & $\mathrm{~N}$ \\
\hline Antonio Gala & Colaboración habitual. & 1 & - \\
\hline $\begin{array}{l}\text { Sosa Wagner y } \\
\text { Mercedes } \\
\text { Fuertes }\end{array}$ & $\begin{array}{l}\text { Colaboración puntual. Sosa es } \\
\text { eurodiputado por UPyD, y Fuertes } \\
\text { catedrática de Derecho Administrativo. }\end{array}$ & 1 & - \\
\hline Frank Buchwald & $\begin{array}{l}\text { Colaboración puntual. Corresponsal } \\
\text { político del canal público de televisión } \\
\text { alemán } Z D F \text {. }\end{array}$ & 1 & + \\
\hline Raúl del Pozo & Alta. Periodista del medio & 1 & $\mathrm{~N}$ \\
\hline
\end{tabular}

Helene Zuber, corresponsal del semanario Der Spiegel en España y Portugal, afirma que "la mayoría está satisfecha con la forma en que la canciller ha gestionado la crisis de la deuda pública, procurando que Europa no les saliera demasiado cara a los contribuyentes".

Incluso hay firmas tan relacionadas y notorias como la de Hans-GertPöttering, director de la Fundación Konrad Adenauer y eurodiputado por la CDU desde 1979, que defiende en su tribuna "Merkel, lo mejor para Europa" que "con un tercer mandato de Angela Merkel como canciller federal, Alemania podrá trabajar siguiendo estos principios para vencer la crisis económica y financiera que lleva ya cinco años afectando a Europa, y para preparar el continente de cara a los grandes desafíos geopolíticos, económicos y culturales del presente siglo". 
En un tono distinto a la generalidad de lo publicado sobre Angela Merkel en El Mundo, pero con las mismas ideas, se encuentra la columna de Sánchez Dragó, "Hormonas y memeces", que hace una apuesta clara por la canciller con argumentos sustentados en la asociación de atributos masculinos, uso de estereotipos y encasillamientos: "me gustan las políticas con testosterona, como la Merkel (¡jalá haya arrasado!) (...). Eso no significa que carezcan de estrógenos, aunque quizá Frau Angela ande escasilla de ellos. ¿Debería decir Herr Merkel? Llamémosla canciller, que es un sustantivo epiceno, y está resuelto".

Frank Buchwald, corresponsal político del canal público de televisión alemán ZDF, opina en su artículo "La canciller imparable" que "el gran número de votos supone un espaldarazo a su trayectoria como canciller y un reconocimiento a su perseverancia en la gestión de la crisis del euro".

No hay que olvidar las valoraciones negativas, que suponen el $45,45 \%$ del total del año 2013 . Si las frases de apoyo son claras, las de desaprobación lo son aún más. Merkel sigue siendo una figura detestada por la población española, como expresa claramente Manuel Jiménez de Parga (jurista y político español), bajo el seudónimo de Secondat, el 21 de septiembre: "Angela Merkel, a pesar de no sernos simpática, marcha hoy en la primera línea de los poderosos".

El que es a día de hoy director de El Mundo, Casimiro García-Abadillo, explica un día después en "'Angie', un modelo para Rajoy", la que considera la causa de la desafección de los españoles: "La mala imagen de Merkel tiene que ver con la decepción respecto a Europa y el euro (...) Los españoles creen que la crisis ha castigado a los más débiles y consideran que quien ha hecho la distinción entre buenos y malos ha sido precisamente Merkel". Mucho más duro es el juicio de Juan Moreno, colaborador de Der Spiegel (en "Peer-dido, Peer-Avería y Peer-lusconi”, 22 de septiembre):

Al inicio de la campaña electoral, Peer Steinbrück ofrecía algo de lo que Angela Merkel, en los ocho años que lleva al mandato, ha carecido siempre: capacidad de inspirar, de ofrecer una visión de qué Alemania quiere, en definitiva, de liderar. Merkel ha manifestado una falta de convicción política hasta entonces jamás vista en un canciller. Con Merkel los alemanes han sabido que su dirigente es una buena asesora de sus intereses, un personaje postideológico, guiado por encuestas, no por ideas propias.

Para condensar dicha opinión generalizada, el sociólogo alemán Ulrich Beck creó el término merkiavelismo, que explica en "Ser o no ser en Europa" el mismo día:

A los alemanes les encanta Angela Merkel, primero y principal, porque les pide poco, y también porque está poniendo en práctica un nuevo estilo de ejercicio del poder en Europa: el merkiavelismo, una combinación de Maquiavelo y Merkel: “¿Es mejor ser amado o ser temido?”, preguntaba Maquiavelo en El Príncipe. Su respuesta es que "uno debe ser a la vez temido y amado, pero ya que es difícil que ambas cosas vayan de la mano, si hay que renunciar a una de las dos es mucho más seguro ser temido que amado". Merkiavel está aplicando este principio de forma selectiva bajo una nueva fórmula. Fuera de sus fronteras, ha de ser temida; en su país, debe ser amada (...) Neoliberalismo brutal para los de fuera, consenso con un barniz socialdemócrata para los de dentro (...). A fin de cuentas, cambiar de postura es un elemento clave de la política de poder de Merkiavel. Además, salvar el euro y la UE queda muy bien para los libros de Historia.

Tenemos por tanto unas piezas positivas que apuestan por la canciller en caso de que siga la línea económica que ellos consideran adecuada, y unas piezas negativas centradas en su inflexibilidad a nivel europeo (para lo que abogan por la formación de gobierno junto a los socialdemócratas del SPD) y en aspectos personales.

Terminamos el análisis de las piezas de El Mundo sobre Angela Merkel con una opinión de Raúl del Pozo, periodista del medio, en la contraportada del periódico el último día de nuestro periodo de estudio, en la columna titulada "La comadrona", del 24 de septiembre de 2013: "La definen como una egomaníaca sedienta de poder, una conservadora atroz capaz de construir una China de minijobs en lo que fue el Estado del Bienestar (...). Angela es una cocinera magnifica que ha puesto en la parrilla el culo del sur y ha aderezado el plato del ajuste como si fuera un sauerkraut con col agria".

\section{CONCLUSIONES}


Tras el análisis de los resultados obtenidos de la aplicación de la ficha de análisis, retomamos las hipótesis fijadas en la metodología para establecer las conclusiones del estudio. Los objetivos marcados aludían al descubrimiento del posicionamiento del diario El Mundo respecto a Angela Merkel, analizando el corpus seleccionado, así como la evolución de lo publicado y el respeto de los autores a la postura editorial. De estos propósitos se derivaban las hipótesis formuladas:

H1. El Mundo se ha posicionado en contra de Angela Merkel en sus textos de opinión, contribuyendo a formar una imagen negativa de la canciller en la sociedad.

En efecto, los datos arrojados del análisis confirman que El Mundo ha adoptado un posicionamiento mayoritariamente negativo en el conjunto de piezas de opinión analizadas en 2005, 2009 y 2013. En concreto, de los 40 textos estudiados, un $47,5 \%$ presentan un tratamiento negativo de la canciller alemana, un $32,5 \%$ positivo y un $20 \%$ neutro.

Al inicio del artículo veíamos los resultados de la encuesta Transatlantic Trends de 2013, en la que un $82 \%$ de los españoles calificaba de errónea la gestión de la canciller, expresando la fuerte desaprobación del conjunto de los españoles. De ahí surgía el interés en esta investigación, puesto que, teniendo en cuenta el papel de los medios de comunicación en la formación de corrientes de opinión, una cifra tan alta no se forja sólo con la oposición de los medios de la facción ideológica contraria a la ideología propugnada por Merkel.

No nos extraña, por ejemplo, encontrar fragmentos como el siguiente, publicado en El País el 24 de septiembre de 2013 bajo el titular "Mamá ganó las elecciones": "Ahora Angela Merkel tendrá que buscar otro cónyuge dispuesto a formar con ella una pareja similar a la de esas arañas cuyo macho no sólo es más pequeño que la hembra, sino además, cumplida la misión, comestible. A los ciudadanos alemanes esto les preocupa poco. Mamá se encarga de todo". Tampoco es raro leer "La gran responsable de que esta crisis no acabe se llama Angela Merkel" en un titular de un artículo firmado por Ignacio Escolar en Eldiario.es.

Sin embargo, los interrogantes surgen cuando leemos en El Mundo los argumentos negativos que hemos visto en el análisis de resultados. Esto, lejos de constituir un caso puntual, un intento de transmitir al lector una sensación de pluralismo ideológico, es una constante. Las valoraciones negativas de la canciller surcan los editoriales y el resto de textos de opinión, como planteábamos en la segunda hipótesis:

H2. Los autores respetan la línea editorial marcada por el medio en las valoraciones que realizan de Angela Merkel, independientemente de su vinculación institucional.

Los juicios vertidos en los 34 textos firmados siguen un discurso paralelo al de su medio de comunicación. No se observan diferencias notables con los editoriales, respetando desde el giro en el tratamiento que realiza El Mundo antes y después de las elecciones de 2005, hasta el relajamiento de las posturas críticas en 2013.

No importa si el autor está institucionalmente vinculado o no con el medio, pues todos mantienen la línea marcada. Esto no significa que no haya artículos discrepantes con el posicionamiento negativo general del periódico, pues encontramos unamuestra de valoraciones positivas y textos con un posicionamiento claro a favor de la canciller. Sin embargo, el resultado general es negativo también para los textos firmados. La asociación entre ambos se basa en el uso de los mismos argumentos esgrimidos en los editoriales, según el año analizado.

Estamos, por tanto, ante un caso de un posicionamiento editorial no esperable en un periódico como El Mundo, con una línea editorial conservadora y liberal que, en teoría, coincide con las directrices ideológicas del partido de Merkel, la Unión Demócrata Cristiana, y con las medidas que la propia canciller ha llevado a cabo. Además, esta postura es secundada por los autores de los textos de opinión, que reafirman los posicionamientos determinados por el periódico en cada momento, sean miembros del Consejo Editorial, periodistas de la plantilla del diario o colaboradores puntuales.

El hecho de que entre sus autores se encuentren políticos de distinto signo, periodistas de diarios internacionales, sociólogos, catedráticos y un largo etcétera de firmas de renombre, no implica en absoluto diversidad de opiniones. En el Libro de Estilo se recoge que la misión de El Mundo es servir de plataforma al 
pluralismo ideológico de la sociedad. Lejos de este propósito, los textos que hemos analizado van encaminados a cerrar filas, a pesar de los ejercicios de pseudo-independencia de las pocas piezas que parecen nadar a contracorriente de la ideología del medio en un intento de transmitir una ilusión de pluralismo mediático.Los atisbos de diversidad y pluralidad ideológica quedan en papel mojado cuando la generalidad de lo publicado nada en una misma dirección marcada.

H3. Los cambios en el tratamiento de la canciller en los tres momentos electorales responden a criterios esencialmente económicos.

Las apuestas realizadas por el periódico se basan de forma conjunta en las políticas económicas que el medio considera adecuadas. En 2005 Angela Merkel es casi una desconocida para la población española si la comparamos con su notoriedad hoy día. Los textos llaman a la senda reformista y, habida cuenta de la actividad del entonces canciller Gerhard Schröder en esta dirección, cualquiera de las dos opciones (SPD o CDU) eran aceptables. Una vez conocidos los resultados electorales, y viendo peligrar el proyecto de austeridad con los datos de los comicios, las críticas se centran en su falta de liderazgo y la necesidad de un líder fuerte al frente del partido cristiano-demócrata.

Hay que tener en cuenta que Alemania está atravesando una crisis económica, con una cifra récord de parados que no se veía desde la Segunda Guerra Mundial. Las llamadas del periódico a las políticas económicas de austeridad son de aplicación interna en el país germano para que, en consecuencia, se posicione como locomotora de Europa.

Pero la situación en 2009 es completamente diferente, puesto que afecta a España directamente. Ya no se la evalúa por las medidas dentro de sus fronteras, pues es parte activa de las decisiones europeas. Una vez superada la crisis en Alemania, El Mundo hace un claro llamamiento en sus textos editoriales a las políticas de rebajas fiscales, en plena crisis económica en nuestro país. No apoya a la canciller, sino unas medidas liberales concretas aplicadas por un gobierno de la CDU, independientemente de quién esté al frente de ellas.

En 2013, si bien siguen predominando las piezas de opinión posicionadas de forma negativa respecto a la canciller, la diferencia entre éstas y las positivas se atenúa de forma considerable. Es el año que más textos opinativos se le dedican, pues Angela Merkel tiene una posición aún más notoria en el contexto europeo. Para los españoles, no hay recortes por parte de su Gobierno, ni medidas de la Unión Europea: hay austeridad dictada por Merkel.

Las políticas económicas siguen determinando el posicionamiento del periódico. Este año El Mundo considera que lo más beneficioso para España sería un Gobierno de coalición formado por CDU y SPD, puesto que con la entrada de los socialdemócratas cabría la posibilidad de que Angela Merkel fuese más flexible en determinadas medidas como la mutualización de la deuda mediante la emisión de eurobonos. La ideología se reduce a la coyuntura económica del momento.

Con todo lo expuesto, no es de extrañar que la señora Merkel -como se le denomina en muchos textos de la prensa española- sea, en opinión de la ciudadanía española, la reina no coronada de Europa, la nueva Dama de Hierro, Merkiavelo, la insensible canciller de la austeridad y la madre que arrulla a su nación, pero no a la nuestra.

Los medios de comunicación son los responsables de la imagen que tenemos de la canciller. Nos dan las palabras, los argumentos y los motivos que interiorizaremos y después repetiremos en nuestros círculos sociales. Y este efecto se maximiza ante un pluralismo inexistente y una falsa diversidad ideológica transmitida por firmas a las que se les presupone ser independientes, pero que siguen el dictamen del medio en cuestión.

Lo preocupante es que no tengamos en cuenta quién nos ha dado esas palabras que consideramos nuestras, de qué modo, y con qué fin. La prensa no informa, sino que moldea. Crea corrientes de pensamiento único encaminadas a defender posturas muy concretas al servicio de intereses que se van alejando del ámbito periodístico conforme se acercan al mercantil. Y si la corriente propugnada apunta hacia la misma dirección incluso en medios de tendencias ideológicas opuestas, se requiere, cuanto menos, estudios que profundicen en las re-construcciones de la realidad que realizan los medios de comunicación para nuestra sociedad. 


\section{REFERENCIAS BIBLIOGRÁFICAS Y HEMEROGRÁFICAS}

\section{Libros}

DOMENACH, J.M. (1955). La propaganda política. (2a ed). Buenos Aires: Eudeba.

EI MUNDO (1996).Libro de estilo/ El Mundo. Madrid: Temas de Hoy.

ESCRIBANO, A. (2008). Comentario de textos interpretativos y de opinión. Madrid: Arco/Libros.

LIPPMANN, W. (2003). La opinión pública. Madrid: Cuadernos de Langre.

NOELLE-NEUMANN, E. (2011). La espiral del silencio: opinión pública, nuestra piel social. Barcelona: Paidós. KAPUŚCIŃSKI, R. (2007). Los cínicos no sirven para este oficio: sobre el buen periodismo. Barcelona: Anagrama.

\section{Artículos en revistas}

AUGSTEIN, F.:“Who is Angela Merkel?”London Review of Books, vol.33 (2011), n 14, p. 7.

MARTÍN LÓPEZ, E.: "El análisis de contenido". Revista de estudios políticos, (1963), n 132, pp. 45-64.

\section{Artículos de revistas electrónicas}

GÓMEZ MENDOZA, M.A. (2000). Análisis de contenido cualitativo y cuantitativo: Definición, clasificación y metodología. Revista de Ciencias Humanas [Internet], 20. [Consulta: 5 de septiembre de 2014].

<http://www.utp.edu.co/ chumanas/ revistas/revistas/rev20/gomez.htm>

\section{Artículos de periódicos digitales}

ARAMBURU, F. (2013). Mamá ganó las elecciones. Disponible en: < http://internacional.elpais.com/internacional/2013/09/23/actualidad/1379965055_644568.html> [Acceso el 19 de septiembre de 2014].

EFE. (2010). Los españoles suspenden a Merkel por ser "egoísta", pero tienen buena imagen de Alemania. Disponible en:<http://www.20minutos.es/noticia/ 1609940/0/encuesta-metroscopia/valoracionespanoles/alemania-merkel/> [Acceso el 10 de octubre de 2014].

ESCOLAR, I. (2013). La gran responsable de que esta crisis no acabe se llama Angela Merkel. Eldiario.es [Internet]. 25 de abril. Disponible en: <http://www.eldiario.es/escolar/responsable-crisis-llama-Angela-Merkel_6_ 125697458.html> [Acceso el 24 de octubre de 2014].

\section{Textos obtenidos de instituciones oficiales}

ASOCIACIÓN PARA LA INVESTIGACIÓN DE MEDIOS DE COMUNICACIÓN (2013). Resumen general de resultados EGM [Internet]. Obtenido el 1 de septiembre de 2014 de AIMC: <http://www.aimc.es/-Datos-EGMResumen-General-.html>.

TRANSATLANTIC TRENDS (2013). Informe de resultados [Internet]. Obtenido el 20 de octubre de 2014 de TransatlanticTrends: <http://trends.gmfus.org/files/2013/09/TT-2013-Key-findings-17-09-13-spanish.pdf>.

(1) En las de 2013 le fueron dedicados seis ninots.

\section{Breve semblanza biográfica de la autora}

Miriam Suárez Romero es alumna del programa de Doctorado en Comunicación de la Facultad de 
Comunicación de la Universidad de Sevilla. Tiene un Máster en Comunicación Institucional y Política

Ámbitos. Revista Internacional de Comunicación, n.27, año 2014, cuarto trimestre (invierno).

Recibido: 13/11/2014

Aprobado: 11/01/2015 